\title{
Reconstruction of Crime Scene: Reveals the Truth at Railway Track
}

ISSN: 2578-0042

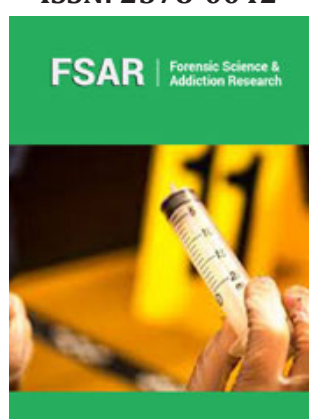

*Corresponding author: Mukesh Sharma, Assistant Director (Physics Div.) State FSL, Jaipur, India

Submission: 漹 September 17, 2021

Published: 此 September 29, 2021

Volume 5 - Issue 4

How to cite this article: Venktesh $\mathrm{V}$, Vashistha KN, Kamlesh Pankaj, Mukesh Sharma. Reconstruction of Crime Scene: Reveals the Truth at Railway Track. Forensic Sci Add Res. 5(4). FSAR. 000621. 2021.

DOI: 10.31031/FSAR.2021.05.000621

Copyright@ Mukesh Sharma, This article is distributed under the terms of the Creative Commons Attribution 4.0 International License, which permits unrestricted use and redistribution provided that the original author and source are credited.

\author{
Venktesh V ${ }^{1}$, Vashistha $\mathrm{KN}^{2}$, Kamlesh Pankaj ${ }^{3}$ and Mukesh Sharma ${ }^{4 *}$ \\ ${ }^{1}$ Assistant Director (Biology Div.), Regional FSL, India \\ ${ }^{2}$ Assistant Director (Serology Div.), Regional FSL, India \\ ${ }^{3}$ In-charge, Mobile Forensic Science Unit, India \\ ${ }^{4}$ Assistant Director (Physics Div.) State FSL, India
}

\begin{abstract}
Reconstruction of a scene of occurrence are generally based two folds 1) scientific experimentation and 2) past experiences of the experts team. The recon involves collection, consideration, happenings and incorporation of all investigative information with physical evidence analysis and interpretation molded into a reasonable explanation of the crime and its related events, which was available with the investigating agency. In this article we have reported a very interesting case study of railway track, as reported our team has been called after six month of the crime scene happenings to reconstruct the spot of occurrence and provide a scientific path to the investigating agency. Our team consists of Biology, Serology and Physics experts, and we reconstructed the scene, with full scientific evidences and analytical aspect. On the basis of our report the case is now disposed. Before our report the case was registered under the section of kidnapping and murder in IPC.
\end{abstract}

\section{Introduction}

Reconstruction of a crime scene are based on the results of crime scene examination, laboratory analysis, and other independent sources of information to reconstruct case events, which are available with investigating agency. Reconstruction often involves the use of inductive and deductive logic, statistical data, and information from the crime scene, pattern analysis, interpretation of physical evidence and laboratory analysis results on a variety of physical evidence [1,2]. Reconstruction of a crime scene almost very complex task in each and every situation like linking many types of physical evidence, stain pattern information, analytical results, investigative information, and other documentary and testimonial evidence into a complete entity [3]. A team of expert may reveal the truth of the scene of occurrence and link the happening with the silent witnesses.

\section{Types of reconstruction}

There are many types of reconstruction depending on the nature of the crime like suicidal reconstruction, road accident reconstruction, crash reconstruction and death investigation. The questions needed to be answered with the scientific evidence and collaborative evidence like testimonials, Call Data records, tower locations etc. Importance of types of events that have taken place and a reconstruction that is based on the degree of involvement of the experts Figure 1. As shown in the outline below, there are five common ways to classify the types of reconstruction services that may occur [4]. 


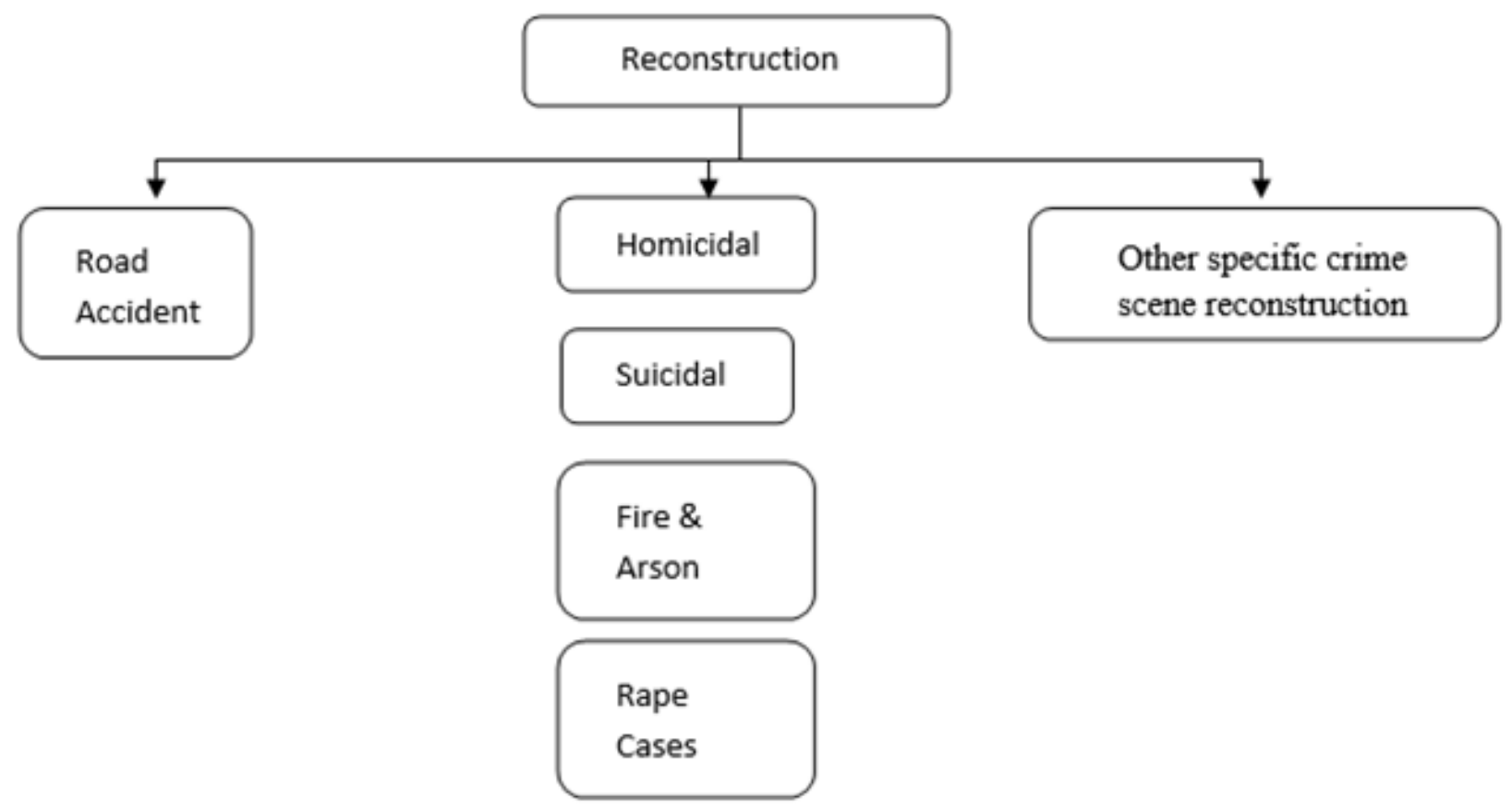

Figure 1: Classifications of reconstruction of scene of crime.

\section{General classifications of reconstruction types}

A. Specific type of incident reconstruction, while specific crime reconstruction required step by step analysis within the defined manner and events reconstruction as 1 Sequence determination 2 Directional determination 3 Position determination 4 Relational determination 5 Conditional determination 6 Identity determination

B. The degree of involvement reconstruction is mainly four folded as 1) Total case reconstruction 2) Partial case reconstruction 3) Limited event reconstruction and 4) Specific pattern reconstruction (like blood stained pattern analysis)

C. Specific type of physical evidence reconstruction: 1 Pattern evidence 2 Shooting investigation evidence (encounter or face encounter etc.) 3 Serological evidence (Blood and rape scene of crime prove)

D. Special areas or determinations in reconstruction (based on MO and Psychological study): Criminal profiling-including MO, motive, and psychological determinations, or organized or disorganized crime scene determination. Scene profilingPrimary scene or secondary scene determination, etc.

To demonstrate through the article, the reconstruction of an event, the criminal act, will be discussed using the classification based on the specific type of physical evidence created by the event and found at the crime scene. This reconstruction process will follow the 'information gathering processes as shown above that leads to the reconstruction theory. The theory incorporates all the previously discussed processing of the crime scene with its physical evidence and the investigator's knowledge of the value and use of forensic testing methods. The physical evidence resulting from the crime and found at the crime scene to be discussed with regards to reconstruction will be pattern evidence, shooting investigation evidence, and serological evidence [5-8].

\section{Railway Track Crime Scene Reconstruction as Case Study}

Forensic Examination of Scenes of Railway Accidents, the sites of accident should be jointly inspected and examined by the Forensic Experts, Police and the Railway officials. Photography and videography of the scene should be carried out meticulously, especially of the damaged/ affected parts, equipments and the tracks. Rescue operations should not be adversely effected by the inspecting team and safety of luggage of the passengers and the victims should be given priority. But this case was not like that, the crime scene was related to a person dead body lying found before 06 months back and we have only two evidences (physical) like some photographs of dead body and postmortem report. To start with reconstruction of a crime scene one should determine all the data available and study them thoroughly, by using the STEPS in Figure 2. 


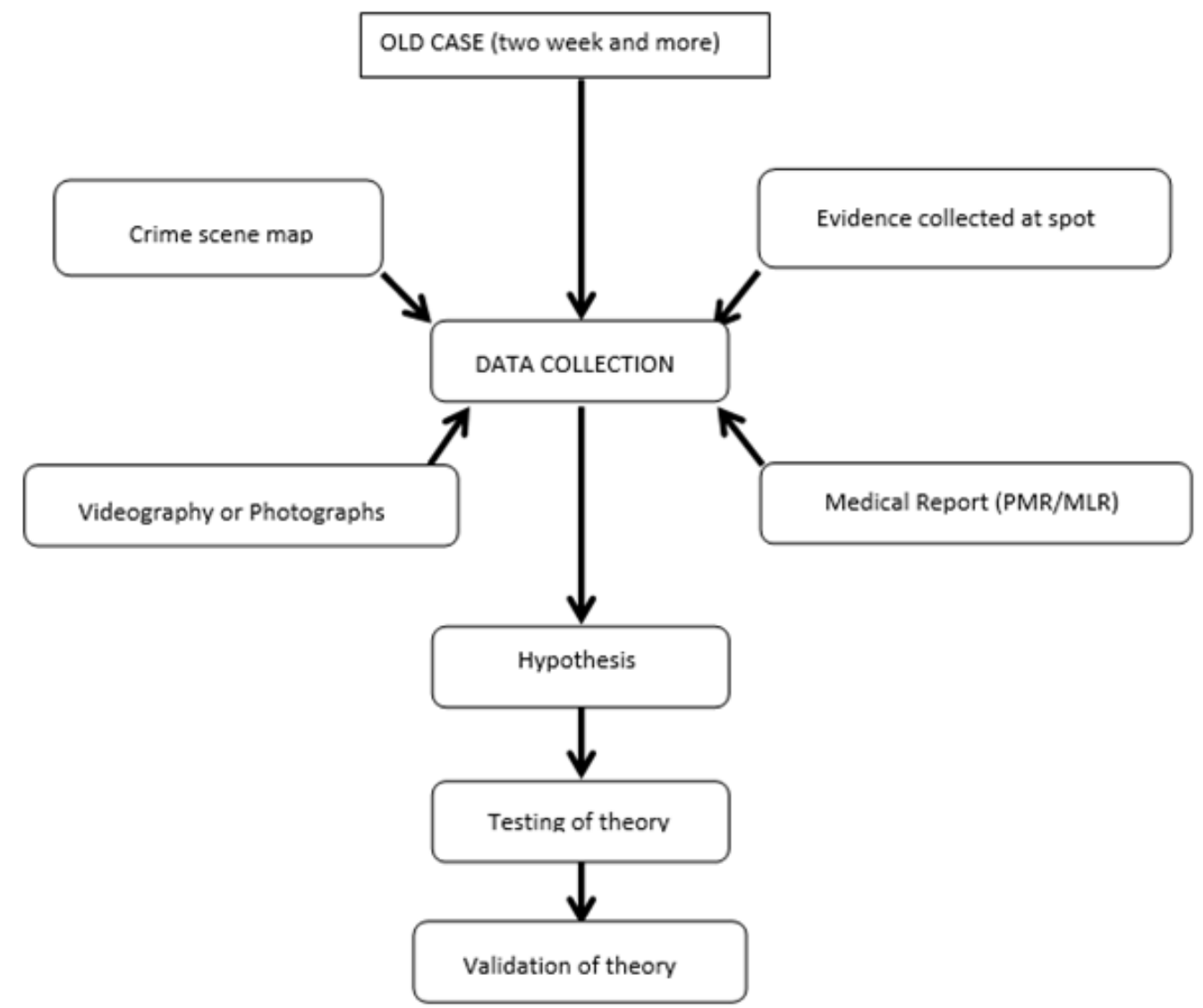

Figure 2: Flow chart for reconstruction of crime scene.

\section{Data collection}

Old photographs, police map (mouka naksha), CDR and PMR: When the team reached to the police station and asks to the IO of the case for all the documents and files before visiting the spot. We read thoroughly the case, analyse the Photos and discussed the PMR with the medical jurist for the same. On the document based study we found that all injuries were anti mortem in nature and blood splashes were scattered all over the track. So no hypothesis was developed. But all photos were indicating to have some information at spot. As per the IO the Call Data Records of the victim and the so called kidnappers were examined thoroughly, the direction and location were not coincided with the theory reported in the FIR and the none of the kidnapper were nearby the location during the period of happening.

Serology and biology work at this case: In this case with the help of the serology and biology experts, we were able to determine the direction of splashes using the older photograph. On the basis of observations, we spotted the exact or closest location, where the crime scene might have occurred. It was confirmed with the help of the railway track supporting staff, those working near the spot, during that period.

Physics work at this case: In the cases we visited the track and again search the spot as per Police file Map (Mouka Naksha).
By applying preliminary test of blood, at the deepest stone on the railway track we decided the spot of occurrence. Then we measure the distances as per Police Map (Mouka Naksha) minimum and maximum distances possible from the spot where in old photograph the blood splashes were observed. By using the inelastic collision theory, keeping the body of victim at rest, we calculated the velocity of the moving train, which came as per calculation of collision theory the initial velocity of the train might be transfer to the body and due to collision the blood splashes should have a length of approximate 82 Feet. At the spot, using the older photos of the scene of crime, we determine the minimum distance was about 78 Feet and maximum was about 86 Feet which correlated our observations.

As per our observations and analysis the experts concluded that the person collide with the training and while collision, he was in about to stand condition. So all the injury were anti mortem in nature, blood splashed were found as per the speed of the train and the speed of the train was also confirmed from the railway staff near the track, they given us the similar data of speed.

\section{Discussion}

The reconstruction of scene of occurrence and the inferences should be drawn on the basis of above-stated physical evidence. Occasionally, track-trail patterns are encountered at crime scenes. Proper interpretation of them can yield information about how 
many persons were present at a scene, whether they were moving about, the nature of the movement (walking, running) and the direction of travel, and whether heavy objects were being carried or dragged. If above-narrated facts are kept in view for safety and examinations, the rate of Railway accidents and derailments can be reduced enormously, which can save huge loss of human lives and property. Not only this, Railway should also pay heed to Human Resource Development (HRD) and the knowledge of technical staff and drivers should be updated from time to time through refresher courses, which will enable them to work with the latest trends in the field. These patterns are more subtle, and require careful observation, as well as extensive knowledge of criminals and details of their previous crimes.

\section{References}

1. Inman K, Rudin N (2001) p 41 in Principle and practice of criminalistics: The profession of forensic science. CRC Press, Boca Raton, FL, USA.
2. Joseph LP, John PR, Pauline JH, Steven I (1986) Forensic science and the courts: The uses and effects of scientific evidence in criminal case processing, NCJRS reports. U.S. Department of Justice, Washington, DC, USA.

3. Gaensslen RE, Harris H, Lee HC (2008) Introduction to forensic science and criminalistics. McGraw-Hill, New York, USA, pp. 61-79.

4. Pyrek KM (2007) Forensic science under siege: The challenge of forensic laboratories and the medico-legal investigation system. Elseiver Press, Burlington, MA, USA.

5. Moriarty JC, Saks MJ (2005) Forensic science: Grand goals, tragic flaws, and judicial gatekeeping. Judges' Journal 44: 16-33.

6. National Medico-legal Review Panel (2011) Death investigation: A guide for the scene investigator (technical update). US department of justice, office of justice programs, Washington, DC, USA.

7. Hawthorne M (1999) First unit responder: A guide to physical evidence collection for patrol officers. CRC Press, Boca Raton, FL, USA.

8. Lee HC, Palmbach TM, Miller M (2001) Henry lee's crime scene handbook. Academic Press, San Diego, USA.

For possible submissions Click below: 